\title{
Efficacy and Safety of Triple Drug Fixed-Dose Combination of Telmisartan, Amlodipine and Hydrochlorthiazide in the Management of Hypertension
}

\author{
FARUQUI A. ARI , $^{1}$ AMLASELVAM A, ${ }^{1}$ RENUKA SRI RAM ${ }^{1}$
}

\begin{abstract}
Effective BP control is far away from reality in many patients in spite of advancements in many classes of antihypertensive drug therapy. Use of triple drug combination in the management of hypertension have already been established, however this study was conducted to evaluate the efficacy and safety of triple drug fixed dose combination of Telmisartan $40 \mathrm{mg}$, Amlodipine $5 \mathrm{mg}$ and Hydrochlorothiazide $12.5 \mathrm{mg}$. 69 hypertensive patients with seating cuff systolic blood pressure e" $160 \mathrm{mmHg}$ and diastolic blood pressure e" $100 \mathrm{mmHg}$ were enrolled in the study. Patients were prescribed to take triple drug fixed dose combination for 120 days. Patients were evaluated on $30^{\text {th }}, 60^{\text {th }}$ and $120^{\text {th }}$ days of treatment. There was statistically significant $(p<0.000 \mathrm{I})$ decrease in systolic blood pressure from baseline to $30^{\text {th }}, 60^{\text {th }}$ and $120^{\text {th }}$ day of treatment mean $\pm S D(166 \pm / 8.6 \mathrm{mmHg}$ vs. $147 \pm 16.1,137 \pm 14.7$ and I $30 \pm 13.9 \mathrm{mmHg}$ ) respectively. Similar to SBP, decrease in DBP was highly significant $(p<0.000 \mathrm{I})$ from the baseline to the $30^{\text {th }}, 60^{\text {th }}$ and $120^{\text {th }}$ day of treatment $(104 \pm I 1.5 \mathrm{mmHg}$ vs. $93.7 \pm 12.3,89 \pm 10.2$ and $84.5 \pm 8.98$ $\mathrm{mmHg}$ respectively). Moreover at the end of the study period of 120 days $85.7 \%$ and $87.8 \%$ patients of age group $>60$ years and $<60$ years respectively achieved the JNC VIII recommended goal. This triple drug fixed dose combination of Telmisartan, Amlodipine and hydrochlorothiazide was found to be effective and safe option for the optimal management of hypertension.
\end{abstract}

Key words: Diastolic, Systolic, Blood Pressure, Hypertension, Triple drug fixed dose combination.

\section{Introduction:}

Individuals with uncontrolled blood pressure (BP) is a major healthcare issue and are at high risk of cardiovascular disease (CVD) morbidity and mortality. ${ }^{1}$ The World Health Organization has concluded that hypertension is the major factor responsible for the most deaths worldwide (12.8\% per year). ${ }^{2}$ It was observed in a meta-analysis of 61 studies involving more than a million patients with hypertension that reducing systolic blood pressure (SBP) as well as diastolic blood pressure (DBP) reduces cardiovascular events. ${ }^{3}$ Furthermore every 2 mmHg decrease in mean SBP results into $7 \%$ reduction in the risk of ischemic heart disease mortality, and a $10 \%$ reduction in the risk of stroke mortality. ${ }^{4}$ The ultimate goal of antihypertensive therapy is to reduce cardiovascular and renal morbidity and mortality.Thus the key objective is to reduce BP effectively, as it reduces mortality and morbidity associated with CVD. Effective BP control is far away from reality in many patients in spite of advancements in many therapies.

1. Health Care Center, NSR Road, Saibaba Colony, Coimbatore11, Tamil Nadu, India.

Correspondence: Dr. Faruqui A. Arif, Health Care Center, NSR Road, Saibaba Colony, Coimbatore-11, Tamil Nadu, India. E-mail: drfaruqui@gmail.com, Tel:+919594977884
Numerous clinical trials consistently established the fact that multiple antihypertensive therapies are often required to achieve BP control. Based on cumulative data from different clinical trials, it has been estimated that at least $25 \%$ of patients will require triple-combination therapy to achieve BP control. ${ }^{5}$

Poor patient adherence due to multiple pills can lead to non achievement of target BP goal set by JNC VIII (Seventh Report of the Joint National Committee on Prevention, Detection, Evaluation, and Treatment of High Blood Pressure). Fixed-dose single-pill combination therapies have been associated with better patient adherence. ${ }^{1}$ This approach may facilitate better clinical outcomes, compared with traditional and time-consuming stepped care and add-on algorithms for the management of hypertension.

This study was conducted to find out the efficacy and tolerability of fixed dose combination of Telmisartan, Amlodipine and Hydrochlorothiazide in the management of hypertension uncontrolled with dual therapy.

\section{Materials and methods}

This was a post marketing, non-randomized, open, noncomparative, study conducted at 2 centres. The triple drug fixed dose combination of Telmisartan $40 \mathrm{mg}$, Amlodipine 5 
mg and Hydrochlorothiazide $12.5 \mathrm{mg}$ was administered to hypertensive patients once daily for 4 months (120 days). Informed consent was obtained from the patients \& the post marketing surveillance was in accordance with the principles laid down in declaration of Helsinki.

\section{Inclusion criteria}

Both male and female hypertensive patients on dual therapy aged $\geq 45$ years old with seated cuff $\geq 160 \mathrm{mmHg}$ and DBP $\geq 100 \mathrm{mmHg}$ and who were willing to give informed consent were included.

\section{Exclusion criteria}

Patients with any condition which in the opinion of the investigator makes the patient unsuitable for inclusion like; known or suspected secondary hypertension, history of asthma or angina, female patient who was pregnant or willing to get pregnant, and patients with known hypersensitivity to any of the ingredient of the fixed dose combination were excluded from the study.

\section{Patient distribution}

Out of 69 patients 34 were male and 35 were female patients were in the age range of 45-98 years old (Table-I).

\section{Efficacy and safety evaluations}

The efficacy variables included two outcome measures: 1. Primary outcome and 2 . Secondary outcome.

Primary outcomeMeasures: SBP and DBP were included in primary outcome, which were evaluated at $30^{\text {th }}, 60^{\text {th }}$ and $120^{\text {th }}$ day of treatment.

Secondary OutcomeMeasures: It includes global assessment of efficacy and safety. Investigator assessed the efficacy by using a three point scale as poor, good and excellent. Poor was for those patients, whose BP did not change from baseline, good when BP changed by $15 \%$ from the baseline and excellent for those who achieved the target $\mathrm{BP}<150 / 90$ for elder patients aged above 60 year and 140/90 for those aged less than 60 years or hypertensive with complication set by JNC VIII.

Global assessment regarding safety was evaluated by recording any adverse event or any complaint during the therapy in every visit. Safety outcomes include mainly symptoms related to hypotension like blurred vision, confusion, dizziness, nausea or vomiting, weakness etc. Patients were interviewed and asked about the type of adverse events throughout the study.

\section{Statistical analysis}

Data analysis on patient demographics and various outcome measures were performed using graph pad prism 6 .
Comparison between the baseline values with the value on the $30^{\text {th }}, 60^{\text {th }}$ and $120^{\text {th }}$ day of treatment were made, as well as comparison in between these days were made by applying one way analysis of variance \& the Turkeys multiple comparison test. Value of $\mathrm{P}<0.05$ were considered as significant.

\section{Results}

Systolic blood pressure (SBP) and Diastolic blood pressure (DBP) was recorded. In addition, overall efficacy and tolerability was assessed at the end of the study period. The baseline characteristics of patients are summarized in the Table-I.

Table-I

Baseline characteristics of patients

\begin{tabular}{lc}
\hline Sex (Male/Female) ratio & $34 / 35$ \\
\hline Age (yrs) range & $45-98$ \\
Number patients $>60$ years & 28 \\
Number patients $<60$ years & 41 \\
SBP (Mean \pm SD)mm Hg & $166 \pm 18.6$ \\
DBP $($ Mean \pm SD)mm Hg & $104 \pm 11.5$ \\
\hline
\end{tabular}

\section{Systolic Blood Pressure (SBP)}

The SBP was measured at base line and then subsequently at $30^{\text {th }}, 60^{\text {th }}$ and $120^{\text {th }}$ days of treatment. The baseline SBPMean \pm SD was $166 \pm 18.6 \mathrm{mmHg}$. The mean SBP at $30^{\text {th }}$, $60^{\text {th }}$ and $120^{\text {th }}$ days of treatment were $147 \pm 16.1 \mathrm{mmHg}$, $137 \pm 14.7 \mathrm{mmHg}$ and $130 \pm 13.9 \mathrm{mmHg}$ respectively. There was statistically highly significant $(\mathrm{p}<0.0001)$ decrease in SBP from the baseline to the $30^{\text {th }}, 60^{\text {th }}$ and $120^{\text {th }}$ day of treatment (Table II, Fig. 1). SBP were decreased by $-19 \pm$ $2.5 \mathrm{mmHg},-29 \pm 3.9 \mathrm{mmHg}$ and $-36 \pm 4.7 \mathrm{mmHg}$ from the baseline to $30^{\text {th }}, 60^{\text {th }}$ and $120^{\text {th }}$ day of treatment respectively.

Table-II

Effect of triple drug therapy on SBP

\begin{tabular}{lcccc}
\hline & Baseline & Day $30 * * *$ & Day $60 * * * \$$ & Day $120 * * * \$ \$ \$$ \\
\hline Mean \pm SD & $166 \pm 18.6$ & $147 \pm 16.1$ & $137 \pm 14.7$ & $130 \pm 13.9$ \\
$\mathrm{mmHg}$ & & & & \\
\hline
\end{tabular}

*** $\mathrm{p}<0.0001$ vs. baseline, $\$ \mathrm{p}<0.01$ vs. day 30th, $\$ \$ \mathrm{p}<0.0001$ 


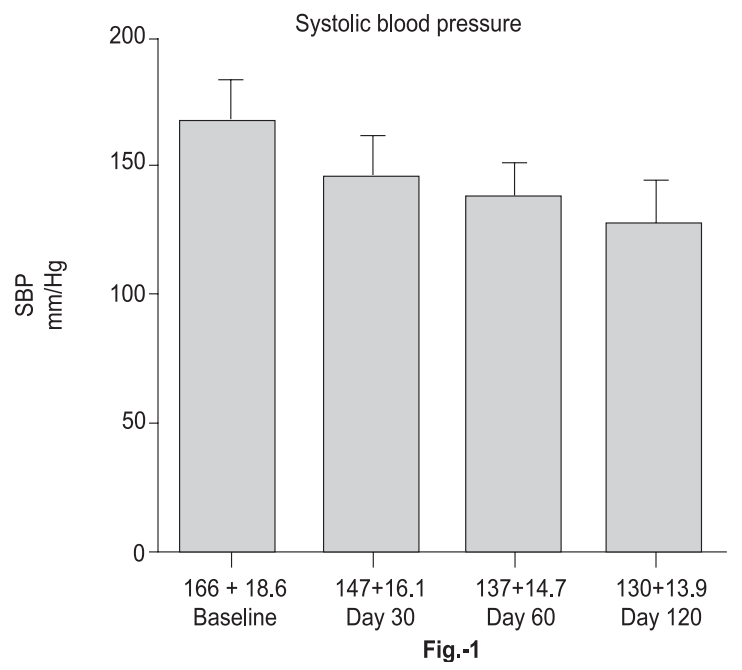

Fig.-1: Effect of triple drug fixed dose combination of Telmisartan,Amlodipine and Hydrochlorothiazide on systolic blood pressure.

\section{Diastolic blood pressure (DBP)}

The DBP was measured at base line and then subsequently at $30^{\text {th }}, 60^{\text {th }}$ and $120^{\text {th }}$ days of the treatment. The baseline DBP (Mean \pm SD) was $104 \pm 11.5 \mathrm{mmHg}$. The mean DBP at $30^{\text {th }}, 60^{\text {th }}$ and $120^{\text {th }}$ days of treatment were $93.7 \pm 12.3 \mathrm{mmHg}$, $89 \pm 10.2 \mathrm{mmHg}$ and $84.5 \pm 8.98 \mathrm{mmHg}$ respectively. Similar to SBP there was highly significant $(\mathrm{p}<0.0001)$ decrease in DBP from the baseline to the $30^{\text {th }}, 60^{\text {th }}$ and $120^{\text {th }}$ day of treatment (Table III, Fig. 2). There was insignificant change between the value of $30^{\text {th }} \& 60^{\text {th }}$ day and similarly in between $60^{\text {th }}$ and $120^{\text {th }}$ day of treatment. Changes in DBP were $10.3 \pm 0.8 \mathrm{mmHg}$, $15 \pm 1.3 \mathrm{mmHg}$ and $19.5 \pm 2.52 \mathrm{mmHg}$ from the baseline to $30^{\text {th }}, 60^{\text {th }}$ and $120^{\text {th }}$ day of treatment respectively.

Table-III

Effect of triple drug therapy on SBP

\begin{tabular}{lcccc}
\hline & Baseline & Day $30 * * *$ & Day $60 * * *$ & Day $120 * * * \$$ \\
\hline $\begin{array}{l}\text { Mean } \pm \text { SD } \\
\text { mmHg }\end{array}$ & $104 \pm 11.5$ & $93.7 \pm 12.3$ & $89 \pm 10.2$ & $84.5 \pm 8.98$ \\
\hline
\end{tabular}

${ }^{* * *} \mathrm{p}<0.0001$ vs. baseline, ${ }^{\$} \mathrm{p}<0.0001$ vs. day $30^{\text {th }}$

\section{Achievement of JNC VIII goal}

Target BP goal set by JNC VIII (Seventh Report of the Joint National Committee on Prevention, Detection, Evaluation, and Treatment of High Blood Pressure) based on age and complications. Recommended target goal for patients $>60$ years old is $150 / 90 \mathrm{mmHg}$ and $140 / 90$ for patients of age $<60$ years. During the treatment and after the treatment following are the percentage of patients achieving the target BP goal (Table IV, V)

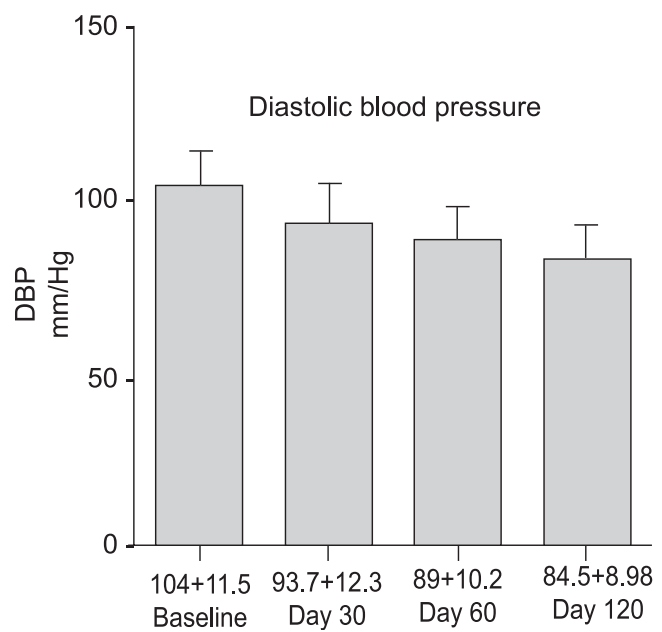

Fig.-2: Effect of triple drug fixed dose combination of Telmisartan,Amlodipine and Hydrochlorothiazide on diastolic blood pressure.

Table-IV

Percentage of patients ( $>60$ years) achieving the target BP $(<150 / 90 \mathrm{mmHg})$

\begin{tabular}{|c|c|c|c|}
\hline & Day 30 & Day 60 & Day 120 \\
\hline$\%$ of patients (n & 3/28) 46.4\% & (23/28) 82.1\% & (24/28) 85.7 \\
\hline
\end{tabular}

Table-V

Percentage of patients ( $<60$ years) achieving the target BP $(<140 / 90 \mathrm{mmHg})$

\begin{tabular}{lccc}
\hline & Day 30 & Day 60 & Day 120 \\
\hline \% of patients (n) & $(17 / 41)$ & $(28 / 41)$ & $(36 / 41)$ \\
& $41.46 \%)$ & $68.9 \%$ & $87.8 \%$ \\
\hline
\end{tabular}

\section{Global assessment of efficacy and tolerability}

Three point scale as poor, good and excellent were used by investigator to assess about the overall efficacy of triple drug fixed dose combination of Telmisartan, Amlodipine and Hydrochlorothiazide. Efficacy was considered poor if blood pressure (BP) did not change from baseline, good when BP changed by $15 \%$ from the baseline and excellent for those who achieved the JNC VIII recommended target BP after the completion of the study of 4 months (120 days). At the end of therapy i.e. 120th day of treatment $86.9 \%$ (60/ 69) showed excellent efficacy, 8.6\% (6/69) showed efficacy as good, and $4.34 \%$ (3/69) showed poor efficacy.The patients were interviewed at every visit for the detection of any side effects.

\section{Discussion:}

The primary goal in the management of hypertension should be effective control of BP in order to restrict, reverse or 
delay the succession of complications without adversely affecting the quality of life.

Most guidelines are agreeing that majority of patients need combination therapy and are now more frequently recommended. ${ }^{6}$ Triple drug combination with synergistic and complementary mechanisms of action is a logical option for the management and control of moderate to severe hypertension. ${ }^{7}$ Moreover benefits of the triple drug combination in one tablet are to improve patients' adherence and compliance in order to achieve the optimal blood pressure control.

Use of triple drug combination in the management of hypertension with clinical benefits have been already established, however this study was conducted to evaluate the efficacy and safety of triple drug fixed dose combination of Telmisartan, Amlodipine and Hydrochlorthiazide.

Result of the present study is either better or comparable to the previous studies. A study conducted by Bhatt et al, on triple drug combination of ARB (angiotensin receptor blocker) + CCB (calcium channel blocker) + Diuretic reported at $60^{\text {th }}$ and $120^{\text {th }}$ day of treatment $79 \%$ \& $89 \%$ of patients achieving the JNC VII target BP respectively. ${ }^{8}$ Present study reported $82.1 \%$ and $85.7 \%$ of patients of age group above 60 years achieved the target $\mathrm{BP}$ goal $(150 / 90 \mathrm{mmHg})$ at $60^{\text {th }}$ and $120^{\text {th }}$ day of treatment respectively. Similarly patients of age group less than 60 years reported that $68.9 \%$ and $87.8 \%$ achieved the target BP $(140 / 90 \mathrm{mmHg})$ at $60^{\text {th }}$ and $120^{\text {th }}$ days of treatment respectively.

Similarly a study conducted by Khemchandani et al used the same triple drug combination for 2 months (60 days) in the management of hypertension \& reported that $65 \%$ and $85 \%$ of patients achieved the target BP at $30^{\text {th }}$ and $60^{\text {th }}$ day of treatment respectively. ${ }^{9}$ Result of the present study is comparable at the $60^{\text {th }}$ day which is $82.1 \% \& 68.9 \%$ for the patients of age group $>60$ and $<60$ years respectively.

Regarding the reduction in SBP, outcome of the present study supports the findings reported in earlier studies. A study conducted by Destroet al used the triple drug combination for 8 weeks in the management of hypertension showed a significant reduction in mean seated blood pressure (msBP) by $-30.5 /-13.8 \mathrm{mmHg}$, which is almost similar to present study as at $60^{\text {th }}$ (approx.9weeks) and $120^{\text {th }}$ days (approx.17 weeks) day of treatment where msBP was reduced by $-29 /-15 \mathrm{mmHg}$ and $-36 /-19.5 \mathrm{mmHg}$ respectively. ${ }^{10}$ It is clear that in the present study reduction in $\mathrm{msBP}$ at $60^{\text {th }}$ day is comparable to the results of earlier study of $8^{\text {th }}$ week.

Similarly a study conducted by Abhichandani et al on triple drug combination (ARB+CCB+Diuretic) in the management of hypertension with or without co morbidities for 120 days. ${ }^{11}$ Result of the present study in terms of decrease in SBP/DBP is better than the study conducted by Abhichandani et al ($29 \pm 3.9 / 15 \pm 1.3 \mathrm{mmHg}$ vs. $-19 \pm 2.61 /-16.6 \pm 1.38$ and $-36 \pm 4.7 /$ $19.5 \pm 2.52$ vs. $-25 \pm 4.07 /-21.6 \pm 1.37 \mathrm{mmHg}$ at $60^{\text {th }}$ and $120^{\text {th }}$ days of treatment).

Thus the results of the present study are better or in comparable to the results of the earlier study regarding the reduction in SBP, DBP achievement JNC VIII recommended target BP. Treatment was well tolerated and 3 out of 69 patients (4.3\%) complained about the side effects like headache, general weakness and dizziness. Side effects were mild and did not compel the patients to stop the therapy. Overall no safety concern for treatment was identified.

\section{Conclusion:}

Triple drug fixed dose combination therapy of Telmisartan, Amlodipine and Hydrochlorothiazide is an effective, safe and convenient treatment strategy in controlling the blood pressure and achieving the desired blood pressure goal.

\section{Conflict of interest: Nil}

\section{References:}

1. Benjamin J. Epstein, PharmD, BCPS, Niren K. Shah, PharmD, Nancy L. Borja-Hart; Management of Hypertension with Fixed-Dose Triple-Combination Treatments.Ther Adv Cardiovasc Dis. 2013;7(5):246-259.

2. Ezzati M, Lopez AD, Rodgers A, Hoorn SV, Murray CJL and the Comparative Risk Assessment Collaborating Group. Selected major risk factors and global and regional burden of disease. Lancet 2002; 360: 1347-60.

3. Gupta R \& Guptha S. Strategies for initial management of hypertension. Indian J Med Res 2010; 132: 531-542.

4. Lewington S, Clarke R, Qizilbash N, et al. Age-specific relevance of usual blood pressure to vascular mortality: a meta-analysis of individual data of one million adults in 61 prospective studies. Lancet 2002; 360: 1903-13.

5. Gradman AH. Rationale for triple-combination therapy for management of high blood pressure. J ClinHypertens (Greenwich). 2010; 12(11): 869-78.

6. Mancia G and Dominiczak A. Guidelines for the management of arterial hypertension: the task force for the management of arterial hypertension of the European Society of Hypertension (ESH) and of the European Society of Cardiology (ESC). Journal of Hypertension 2007; 25: 1105-1187.

7. Monica Doménech, Antonio Coca. Role of triple fixed combination valsartan, amlodipine and hydrochlorothiazide 
in controlling blood pressure.Patient Preference and Adherence 2010; 4: 105-113.

8. Anil K. Bhatt, Faruqui A.A. Management of hypertension with fixed-dose triple drug combination of telmisartan, amlodipine and hydrochlorothiazide. Int J ClinSurgAdv 2014; 2(1):12-20.

9. Khemchandani D, FaruquiA.A. efficacy \& safety of oral triple drug combination of telmisartan, amlodipine and hydrochlorothiazide in the management of non-diabetic hypertension International Journal of Innovative Research and Review 2013; 1(2):37-41.
10. Destro M, Crikelair N, Yen J and Glazer R. Triple combination therapy with amlodipine, valsartan, and hydrochlorothiazide vs dual combination therapy with amlodipine and hydrochlorothiazide for stage 2 hypertensive patients. Journal of Vascular Health and Risk Management 2010; 6: 821-7.

11. Abhichandani VK, FaruquiA.A. Evaluation of triple drug combination (telmisartan, amlodipine and hydrochlorthiazide) in the management of hypertension Pacific Journal of Medical Sciences 2014; 12(2):1-11. 